\title{
The Interaction between ESRRA and PTH Gene Methylation and Body Mass Index in Post-Menopausal Cases
}

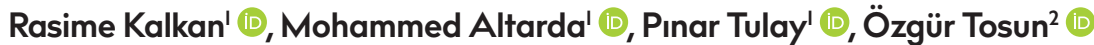 \\ 'Department of Medical Genetics, Near East University School of Medicine, Nicosia, Northern Cyprus \\ 2Department of Biostatistics, Near East University School of Medicine, Nicosia, Northern Cyprus
}

ORCID IDs of the authors: R.K. 000-0002-6095-7352; M.A. 0000-0003-II02-6989; P.T. 0000-0002-6793-7805; 0̈.T. 0000-0003-19959425.

Cite this article as: Kalkan R, Altarda M, Tulay P, Tosun Ö. The Interaction between ESRRA and PTH Gene Methylation and Body Mass Index in Post-Menopausal Cases. Cyprus J Med Sci 2019; 4(3): 247-50.

BACKGROUND/AIMS

Post-menopausal and hormone-related diseases are the biggest problems for women on which genetic and environmental factors have an effect.

\section{MATERIALS and METHODS}

In this study, the methylation status of ESRRA (Estrogen Related Receptor Alpha) and PTH (Parathyroid Hormone) promoters was analyzed in 30 pre-menopausal and 35 post-menopausal women by using MS-HRM (Methylation Sensitive-High Resolution Melting). The height $(\mathrm{cm})$ and weight $(\mathrm{kg})$ of each participant were measured. The statistical analyses were performed and their associations with patient characteristics were evaluated by Pearson's chi-squared test, two-tailed Fisher's exact test, and Mann-Whitney $U$ test $(p<0.05)$

\section{RESULTS}

The PTH gene was methylated in four post-menopausal cases (II.4\%) and unmethylated in 31 cases (88.6\%). The ESRRA gene was methylated in six post-menopausal cases (17.1\%) and unmethylated in 29 cases (82.9\%). There were no significant differences between post-menopause and PTH methylation ( $p>0.005)$; however, a statistically significant association was detected between post-menopause and unmethylation of ESRRA ( $p=0.040)$. Also, no significant differences were detected between body mass index (BMI) and methylation parameters.

\section{CONCLUSION}

Estrogen plays a significant role in the regulation of skeletal homeostasis, lipid and carbohydrate metabolism, and the central nervous system. Researchers showed the relationship among ESRRA, BMl, and fat percentage in animal models. However, we did not find any statistically significant relationship between ESRRA methylation and BMI in post-menopausal women. To the best of our knowledge, this is the first study that investigates the relationship between the methylation of PTH and ESRRA genes, and BMI in post-menopausal cases.

Future epigenetic studies will help to clarify potential effects of gene methylation in post-menopause.

Keywords: Body mass index, estrogen related receptor alpha, methylation, parathyroid hormone, post-menopause

\section{INTRODUCTION}

Estrogen is the important hormonal regulator of female reproductive functions that plays a significant role in the regulation of skeletal homeostasis, lipid and carbohydrate metabolism, electrolyte balance, skin physiology, cardiovascular system, and the central nervous system (I). Genetic and environmental factors have an effect on post-menopausal and hormone-related diseases (2). Lane and colleagues identified the genetic background of menstrual cycle and showed the role of the RANKL/RANK/OPG pathway in timing of the menstrual cycle (3). Genetic, demographic, and reproductive characteristics, lifestyle, and body weight are associated with the timing of menopause (4). Recent studies have focused on the relationship between body mass index (BMI) and the timing of age at menopause, but the results are still inconsistent. For example, Hardy and colleagues noted that an earlier age at menopause is associated with underweight (5). On the other hand, Dratva and colleagues concluded that a higher BMI is associated with earlier menopause (6) but in contrast to this, other researchers noted that there is no association between BMl and menopause timing (7). 
BMI has been widely used as a screening tool for obesity, but it only represents a proxy measure of body fat mass, because it does not take into account differences in genetic or epigenetic factors. BMI was compared between pre-menopausal and post-menopausal women in cross-sectional studies and significant differences were detected between pre-menopausal and post-menopausal women. Previous studies used different parameters like age, energy intake, sex hormone-binding globulin levels, and genetic polymorphisms to be able to show the interaction between obesity or increased $\mathrm{BMI}$ and menopause.

Until now, all of the studies have tried to show the interaction between genetic polymorphisms and obesity, menopause, or age of menopause (8). Few studies have been published which show obesity-related variation in DNA methylation, which were related with global methylation or candidate gene approaches (9).

To better understand the interaction of menopause and $\mathrm{BMI}$, we compared associations between BMI and methylation of ESRRA (Estrogen Related Receptor Alpha) and PTH (Parathyroid Hormone) in pre- and post-menopausal cases.

\section{MATERIALS and METHODS}

For this study, 35 post-menopausal and 30 pre-menopausal women were recruited. Written informed consent was obtained from all of the subjects. The study was performed in accordance with the Declaration of Helsinki and approved by the Research Ethics Committee of the Near East University (YDU/2016/42353). The inclusion criterion for the study was: all post-menopausal ladies (menopause for $>$ | year) and exclusion criteria were: women with un-natural menopause, women who took medications such as anxiolytics, anti-depressants, and exogenous hormones, women who have serious disease or mental retardation, smoking, alcohol usage, and women who have a weight loss therapy, food allergies, heart disease history, insulin-dependent diabetes, type 2 diabetes, kidney disease or liver disease.

Genomic DNA was extracted from blood samples according to the Qiagane AIIPrep DNA/RNA/Protein isolation kit and its quantity was measured using a NanoDrop ND-I000 Spectrophotometer (Thermo Fisher Scientific).

\section{Anthropometry}

The anthropometric data included body weight, height, and BMI (weight/height ${ }^{2}$ ). Body weight was measured to the nearest 0.1 $\mathrm{kg}$ with subjects in a bathing suit following an overnight fast and without shoes, using a calibrated scale. Waist circumference was measured at the midpoint between the lowest rib and the top of the iliac crest using a non-elastic tape. This measurement was performed by a single evaluator.

\section{Determination of PTH and ESRRA Methylation Status}

An EpiTect Bisulfite kit (Qiagen, Manchester, UK) was used for the bisulfite modification reaction and $1.3 \mu \mathrm{g}$ DNA was used for the bisulfite treatment reaction according to the manufacturers' protocol. After conversion, converted DNA was eluted to a final concentration of $30 \mathrm{ng} / \mu \mathrm{l}$. For methylated and unmethylated control, a DNA EpiTect Control DNA Set (Qiagen, Manchester, UK, Cat No./ID: 59568) was used. Methylation of PTH and ESRRA promoters was analyzed in Rotor Gene Q (Qiagen, Manchester, UK) for MS-HRM and primers were designed according to the EpiTect ${ }^{\circ} \mathrm{HRM}^{\text {TM }}$ PCR Handbook (Qiagen, Manchester, UK). The comparable amounts of template genomic DNA for all samples which results in cycle threshold (CT) values below 30 and differing by no more than 3 CT values have been used.

\section{Statistical Analysis}

The statistical analyses were performed and their associations with patient characteristics were evaluated by Pearson's chi-squared test, Fisher's exact test, or Mann-Whitney $U$ test, where appropriate. Calculations were performed using Statistical Package for the Social Sciences 16.0 software (SPSS Inc.; Chicago, IL, USA), with a statistical significance of $p<0.05$

\section{RESULTS}

Methylation data were only available in whole blood. The mean age of 30 pre-menopausal patients was 33.5 years (mean \pm standard deviation, $33.5 \pm 6.9)$ and that of the post-menopausal patients was 56.7 (mean \pm standard deviation, 56.7 \pm 4.9 ).

\section{PTH Methylation and BMI Interaction}

In the study group, the PTH promoter was methylated in four (II.4\%) post-menopausal women and unmethylated in 31 (86.6\%) of the pre-menopausal women (Table I).

In the control group, 8 (26.7\%) of the samples were methylated and $22(73.3 \%)$ of the samples were unmethylated (Table I). There is no statistically significant association between menopause and methylation of the PTH promoter ( $p>0.05$ ) (Figure I). Also, no significant associations between $\mathrm{BMI}$ and methylation parameters were detected ( $p>0.05$ ).

\section{TABLE I. BMI and methylation status of ESSRA and PTH in post and pre-menopausal cases}

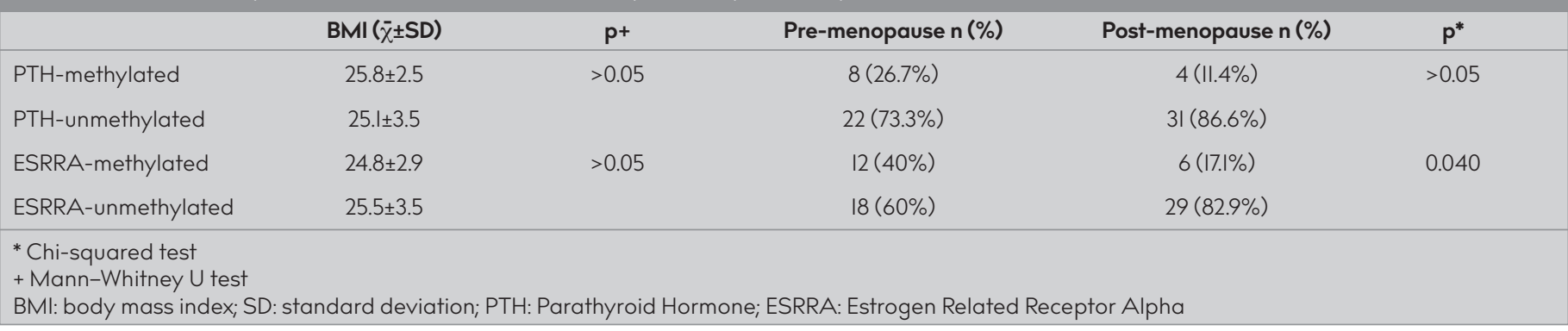




\section{ESRRA Methylation and BMI Interaction}

The ESSRA gene was detected to be methylated in six (17.1\%) post-menopausal cases and unmethylated in 29 (82.9\%) post-menopausal cases. In the control group, the ESRRA gene was methylated in 12 (40\%) cases and unmethylated in $18(60 \%)$ cases (Figure 2). There were statistically significant association between post-menopause and the methylation status of ESRRA $(p=0.040)$. Also, no significant associations between BMI and methylation parameters were detected ( $p>0.05)$ (Table I).

\section{DISCUSSION}

The level of estrogen decreased during the menopause and this causes different physiological and hormonal problems in women. The epigenetic control of the estrogen receptors (ER) regulates the expression of ER target genes and estrogen-regulated processes (I0). The relationship between ESRRA and BMI or fat percentage was studied by several researchers (II). Mueller and colleagues showed the obese phenotype in the Esrra knockout mouse (I2) and concluded that ESRRA plays an important role in energy metabolism (12).

The first BMI-related epigenetic study was carried out by Boyne and colleagues and they did not find significant associations between adiposity and Alu methylation (13). They also tried to show the association between endogenous sex hormone exposure and LINE-I and Alu methylation in post-menopausal

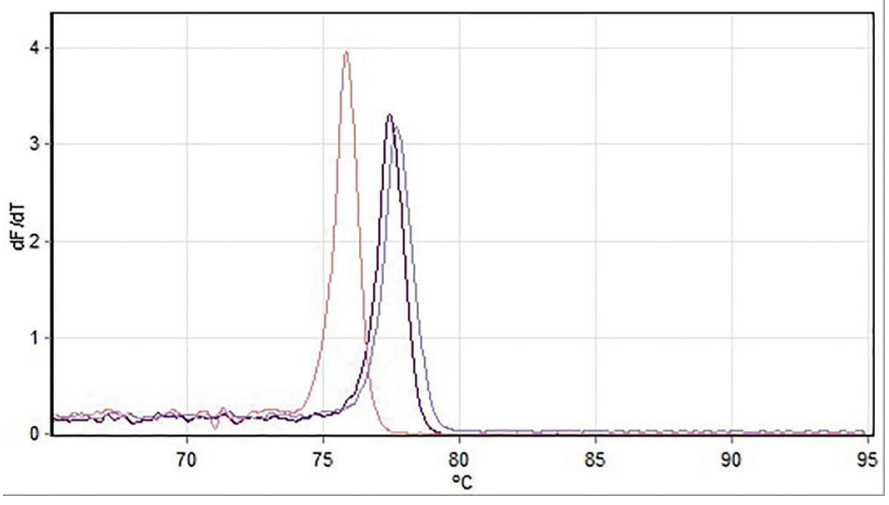

FIGURE I. Methylated PTH patient.PTH unmethylated control is shown in red, and methylated control is shown in blue. Patient number 25 was methylated women, and they showed the significant association between LINE-I methylation estradiol and estrone usage (I3). They concluded that the usage of estrogen was associated with repetitive element DNA methylation in post-menopausal women (14). Jintaridith and colleagues showed association between Alu hypomethylation and advanced age and lower bone mass density in post-menopausal cases (I5).

Various genetic and epigenetic studies have been carried out in post-menopausal cases. Epigenetic regulation of post-menopausal status is an interesting field and researchers have tried to show interactions between DNA methylation and BMI, and osteoporosis and age of menopause. Researchers showed the relationship among ESRRA, body mass index (BMI), and fat percentage in animal models.

In this study, we analyzed PTH and ESRRA methylation in post-menopausal cases and tried to find out their interaction with BMI. There were no significant association between post-menopause and PTH methylation ( $p>0.005)$, but a statistically significant association was detected between post-menopause and ESRRA methylation status $(p=0.040)$. Also, no significant differences were detected between BMl and methylation parameters.

To the best of our knowledge, this is the first study investigating the relationship between methylation of PTH and ESRRA genes and $\mathrm{BMI}$ in post-menopause. Future epigenetic studies will help to clarify potential effects of gene methylation in post-menopause.

In conclusion, the present study demonstrates that ESRRA unmethylation is associated with post-menopause but there is no association between PTH and post-menopausal cases. There is no association detected between methylation of ESRRA and PTH and BMI. This study is the first epigenetic study that investigates the ESRRA and PTH methylation in post-menopausal cases.

Although the limited number of sample size in our study and lack of epigenetic studies in this field prove our results crucial, our results showed magnitude of the epigenetic profile of Turkish Cypriot post-menopausal women.

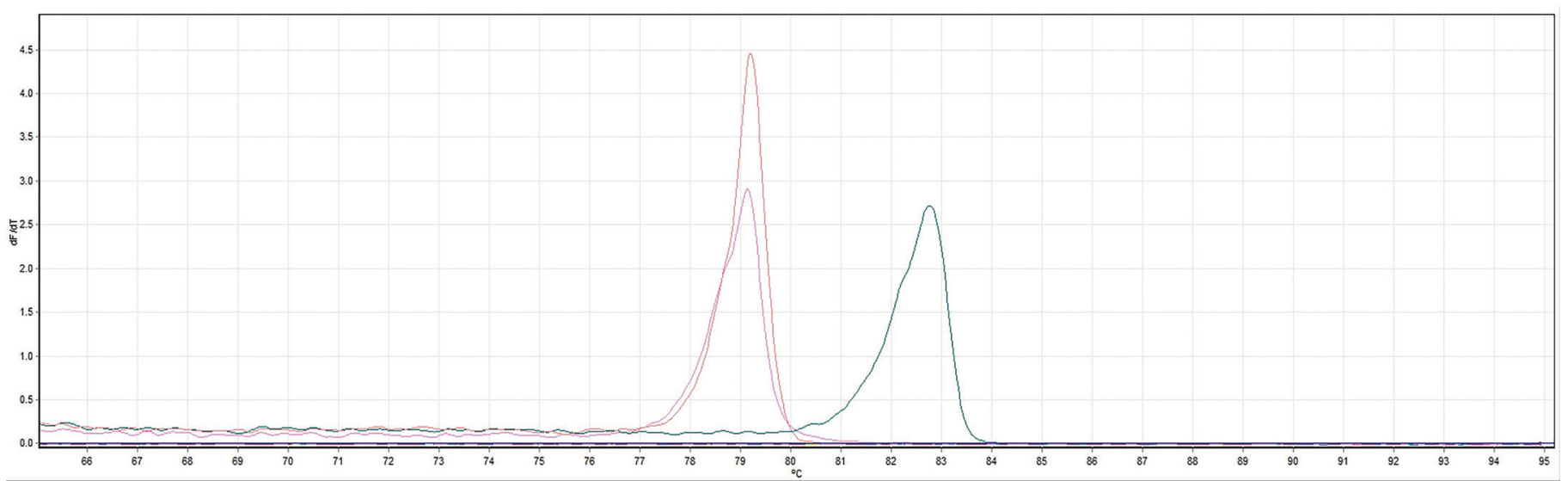

FIGURE 2. Unmethylated ESRRA patient. ESRRA unmethylated control is shown in red, and methylated control is shown in green. Patient number 49 was unmethylated 
Ethics Committee Approval: The study was performed in accordance with the Declaration of Helsinki and approved by the Research Ethics Committee of the Near East University (YDU/2016/42-353).

Informed Consent: Written informed consent was obtained from all of the subjects.

Peer-review: Externally peer-reviewed.

Author contributions: Concept - R.K.; Design - R.K.; Designed - P.T., R.K.; Supervision - R.K., O.T.; Resource - R.K.; Materials - R.K.; Data Collection and/or Processing - R.K., M.A.; Analysis and/or Interpretation - O.T. Literature Search - R.K.; Writing - R.K.; Critical Reviews - R.K., O.T.

Conflict of Interest: The authors have no conflicts of interest to declare.

Financial Disclosure: This study was supported by Near East University Scientific Research Project Unit - Grant Number: SAG-2016-2-0I2.

\section{REFERENCES}

I. Nilsson S, Gustafsson J. Estrogen receptors: therapies targeted to receptor subtypes. Clin Pharmacol Ther 20ll; 89(I): 44-55. [CrossRef]

2. Duan P, Wang ZM, Liu J, Wang LN, Yang Z, Tu P. Gene polymorphisms in RANKL/RANK/OPG pathway are associated with ages at menarche and natural menopause in Chinese women. BMC Womens Health 2015; 15: 32. [CrossRef]

3. Lane D, Matte I, Laplante C, Garde-Granger P, Rancourt C, Piché A. Osteoprotegerin (OPG) activates integrin, focal adhesion kinase (FAK), and Akt signaling in ovarian cancer cells to attenuate TRAIL-induced apoptosis. J Ovarian Res 20I3; 6(I): 82. [CrossRef]

4. Gold EB. The timing of the age at which natural menopause occurs. Obstet Gynecol Clin North Am 20Il; 38(3): 425-40. [CrossRef]

5. Hardy R, Mishra GD, Kuh D. Body mass index trajectories and age at menopause in a British birth cohort. Maturitas 2008; 59:304-|4. [CrossRef]
6. Dratva J, Gómez Real F, Schindler C, Ackermann-Liebrich U, Gerbase MW, Probst-Hensch NM, et al. Is age at menopause increasing across Europe? Results on age at menopause and determinants from two population-based studies. Menopause 2009; 16: 385-94. [CrossRef]

7. Aydin ZD. Determinants of age at natural menopause in the Isparta Menopause and Health Study: premenopausal body mass index gain rate and episodic weight loss. Menopause 2010; 17(3): 494-505. [CrossRef]

8. Liu X, Rao S, Gong C, Li T, Ding L, Wang S, et al. Purinergic P2X7 receptor functional genetic polymorphisms are associated with the susceptibility to obesity in Chinese postmenopausal women. Menopause 2018; 25(3): 329-35. [CrossRef]

9. Kuehnen P, Mischke M, Wiegand S, Sers C, Horsthemke B, Lau S, et al. An Alu element-associated hypermethylation variant of the POMC gene is associated with childhood obesity. PLoS Genet 20I0; 8(3): el002543. [CrossRef]

10. Vrtačnik P, Ostanek B, Mencej-Bedrač S, Marc J. The many faces of estrogen signaling. Biochem Med (Zagreb) 2014; 24(3): 329-42. [CrossRef]

II. Pérusse L, Rankinen T, Zuberi A, Chagnon YC, Weisnagel SJ, Argyropoulos $\mathrm{G}$, et al. The human obesity gene map: the 2004 update. Obes Res 2005; I3(3): 381-490. [CrossRef]

12. Mueller SO, Korach KS. Estrogen receptors and endocrine diseases: lessons from estrogen receptor knockout mice. Curr Opin Pharmacol 200I; I: 613-9. [CrossRef]

13. Boyne DJ, Friedenreich CM, McIntyre JB, Courneya KS, King WD. Associations between adiposity and repetitive element DNA methylation in healthy postmenopausal women. Epigenomics 2017; 9(10): 1267-77. [CrossRef]

14. Boyne DJ, Friedenreich CM, McIntyre JB, Stanczyk FZ, Courneya KS, King WD. Endogenous sex hormone exposure and repetitive element DNA methylation in healthy postmenopausal women. Cancer Causes Control 2017; 28(12): 1369-79. [CrossRef]

15. Jintaridth P, Tungtrongchitr R, Preutthipan S, Mutirangura A. Hypomethylation of Alu elements in post-menopausal women with osteoporosis. PLoS One 2013; 8(8): e70386. [CrossRef] 